\title{
G

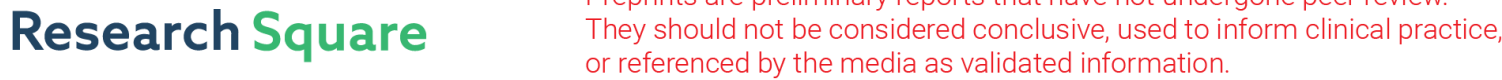 \\ Effect of prophylactic anticoagulation on incidence of venous thromboembolism in testicular germ cell tumor patients
}

\section{Nikola Hapakova}

Comenius University, Faculty of Medicine, National Cancer Institute, Bratislava, Slovakia

\section{Michal Chovanec}

Comenius University, Faculty of Medicine; National Cancer Institute, Bratislava, Slovakia

\section{Katarina Rejlekova}

Comenius University, Faculty of Medicine, National Cancer Institute, Bratislava, Slovakia

\section{Katarina Kalavska}

Comenius University, Faculty of Medicine, National Cancer Institute, Bratislava, Slovakia

\section{Jana Obertova}

Comenius University, Faculty of Medicine, National Cancer Institute, Bratislava, Slovakia

\section{Patrik Palacka}

Comenius University, Faculty of Medicine, National Cancer Institute, Bratislava, Slovakia

\section{Valentina De Angelis}

Comenius University, Faculty of Medicine, National Cancer Institute, Bratislava, Slovakia

\section{Zuzana Sycova-Mila}

Comenius University, Faculty of Medicine, National Cancer Institute, Bratislava, Slovakia Jozef Mardiak

Comenius University, Faculty of Medicine, National Cancer Institute, Bratislava, Slovakia Michal Mego ( $\sim$ misomego@gmail.com )

\section{Research article}

Keywords: testicular germ cell tumors, venous thromboembolism, low molecular weight heparin, prophylaxis, chemotherapy

Posted Date: March 31st, 2020

DOI: https://doi.org/10.21203/rs.3.rs-20044/v1

License: (1) (i) This work is licensed under a Creative Commons Attribution 4.0 International License. Read Full License 
Version of Record: A version of this preprint was published at Journal of Clinical Oncology on February 20th, 2020. See the published version at https://doi.org/10.1200/JC0.2020.38.6_suppl.422. 


\section{Abstract}

Background Testicular germ cell tumors (GCTs) are among the most common solid tumors in young males. With the availability of highly effective treatment, improving patients' quality of life has gained more focus in recent years. Venous thromboembolism (VTE), commonly occurring in GCT patients, is associated with increased morbidity and mortality. Prophylactic anticoagulation has been shown to decrease the risk of VTE in patients with malignancy. The aim of this retrospective study was to evaluate the effect of low molecular weight heparin (LMWH) prophylaxis on incidence of VTE and outcome in GCT patients treated with first-line chemotherapy.

Methods Our study population included chemotherapy-naive GCT patients treated with first-line chemotherapy at the National Cancer Institute, Bratislava, Slovakia from January 2000 to December 2017. VTE was defined as any venous thrombosis or pulmonary embolism, confirmed by imaging, occurring during first-line chemotherapy. Patients diagnosed with VTE on initial staging exam were excluded from the study. No visceral thromboses were observed.

Results Our cohort included 353 GCT patients. LMWH prophylaxis was administered to 104 patients (29.5\%), 249 patients (70.5\%) did not receive prophylaxis. We observed 14 (4.0\%) VTE events. The difference in VTE incidence between patients with and without prophylaxis was not statistically significant $(5.8 \%$ vs. $3.2 \% \mathrm{P}=0.37)$. We have observed a trend to longer overall survival in patients without prophylaxis (hazard ratio $=0.61,95 \%$ confidence interval $=0.32-1.13, \mathrm{P}=0.08$ ). Patients with extragonadal GCT receiving VTE prophylaxis had significantly shorter survival. (hazard ratio $=0.29,95 \%$ confidence interval $=0.08-1.12, P=0.04)$. This effect was most likely driven by higher incidence of treatment related deaths in patients with extragonadal GCT receiving LMWH. $(P=0.06)$

Conclusions LMWH prophylaxis was not associated with decreased VTE incidence. Moreover, there was a higher incidence of treatment related deaths in patients with extragonadal tumor location. LMWH prophylaxis during hospitalization should not be used routinely in GCT patients receiving chemotherapy.

\section{Background}

Testicular germ cell tumors (GCTs) represent one of the most common solid neoplasms in young males between the ages of 15 and 35 and the incidence has been steadily rising in the past decades.[1,2] Cisplatin-based chemotherapy with or without resection of the residual mass are highly effective in the treatment of GCTs with five-year survival rate of more than 95\%.[3] As a result, the number of GCT survivors with long life expectancy is rising. Therefore, maintaining patients' quality of life and minimizing treatment-related morbidity and mortality has gained more significant interest in recent years.

Venous thromboembolism (VTE) commonly occurs in cancer patients.[4] It affects about $10 \%$ of patients with malignancy. The pathophysiology is thought to be multifactorial and is related to the type of tumor, anatomic location, patient's comorbidities, type of treatment, etc.[5] When compared to patients with different type of malignancy, GCT patients have higher incidence of VTE events.[6] 
VTE is associated with increased morbidity and mortality in cancer patients. Levitan et al found more than a threefold higher risk of recurrent VTE and death in cancer patients compared to patients with VTE without cancer diagnosis.[7]

Incidence of VTE in GCT patients has been assessed in a few studies and the results vary widely. Honecker et al observed 9\% VTE incidence in patients before starting chemotherapy, while there was only a $2 \%$ incidence of VTE during first-line chemotherapy.[8] In a different study, Piketty et al found a 14\% incidence of VTE during first-line chemotherapy and $5 \%$ incidence of VTE after chemotherapy.[6]

Several groups focused on identification of risk factors of VTE events in GCT patients. [6, 9-12] Weijl et al observed an increased risk of VTE in patients with liver metastases (odds ratio $=4.9$ ). [10] Piketty et al identified body surface area $>1.9 \mathrm{~m}^{2}$ (relative risk (RR) $=5,95 \%$ confidence interval $(\mathrm{Cl}) 1.8-13.9$ ) and elevated serum lactate dehydrogenase $(\mathrm{RR}=6.4,95 \% \mathrm{Cl} 2.3-18.2)$ as independent risk factors. In their study, patients without any risk factors had $4 \%$ probability of having VTE, while patients with at least 1 risk factor had $26 \%$ probability of having VTE.[6]

Prophylactic anticoagulation has been shown to decrease the risk of symptomatic VTE in cancer patients. ( $\mathrm{RR}=0.56,95 \% \mathrm{Cl} 0.47-0.68)$ [13] Gizzi et al studied the incidence of thromboembolic events in GCT patients treated with first-line chemotherapy and observed lower incidence of thromboembolic events in patients receiving thromboprophylaxis when compared to patients without prophylaxis.[12] However, small number of patients in each subgroup of this study makes the interpretation of the results difficult and larger study is needed to elucidate the relationship between thromboprophylaxis and incidence of VTE in GCT patients undergoing cisplatin-based chemotherapy.

The aim of this retrospective study was to evaluate the effect of low molecular weight heparin (LMWH) prophylaxis on incidence of VTE events and outcome in germ cell tumor patients treated with first-line chemotherapy.

\section{Patients And Methods}

\section{Study patients}

This retrospective study was conducted using the National Cancer Institute medical records database. The study was approved by the Institutional Review Board and waiver of consent form was granted. Patients diagnosed with germ cell tumors treated with first line/adjuvant chemotherapy at the National Cancer Institute, Bratislava, Slovakia from January 2000 to December 2017 were eligible. Patients with any concurrent malignancy, other than non-melanoma skin cancer in the previous 5 years were excluded from the study. Excluded were also patients with previous chemotherapy, patients with venous thromboembolism diagnosed on the initial staging exam and patients on anticoagulation therapy (therapeutic or prophylactic) started before the initiation of first line chemotherapy.

\section{Definition of VTE event}


VTE event was defined as any venous thrombosis or pulmonary embolism occurring between Day 1 of first cycle of the first-line chemotherapy and Day 21 of the last cycle of the first-line chemotherapy. Cases of superficial phlebitis were not classified as events. Every VTE event had to be confirmed by imaging studies, either Doppler ultrasonography or a CT scan. Depending on patients' presenting symptoms, the events were divided into symptomatic and incidental, if discovered on imaging done for a different purpose.

\section{Baseline data}

During the initial staging, patients had a CT scan of the chest, abdomen and pelvis. Baseline data regarding age, primary tumor location, tumor histology, TNM stage, International Germ Cell Cancer Collaborative Group (IGCCCG) risk class and first-line chemotherapy regimen were recorded. Blood coagulation tests were not routinely performed during the initial screening.

\section{VTE prophylaxis}

LMWH prophylaxis was not routinely prescribed before January 2010 during hospitalization. At our institution, all GCT patients are hospitalized during chemotherapy. In December 2007, American Society of Clinical Oncology released clinical practice guidelines recommending prophylactic anticoagulation for hospitalized patients receiving chemotherapy.[14] Therefore, starting in January 2010, we progressively implemented prophylactic anticoagulation with low molecular heparin (nadroparin $0,4 \mathrm{ml}$ or equivalent). However, not all physicians integrated this guideline into their practice and LMWH prophylaxis was prescribed at the individual physician's discretion.

\section{STATISTICAL ANALYSIS}

We performed a retrospective review of patients' medical records. All thromboses or pulmonary embolism, confirmed by imaging modality, were classified as events. Patients' characteristics were tabulated and summarized as the median (range) values for continuous variables and frequency (percentage) for categorical variables, respectively. Fisher's exact test was used for statistical analysis to compare VTE events between groups with and without prophylaxis.

Primary outcome was the overall incidence of VTE events occurring between Day 1 of first cycle of the first-line chemotherapy and Day 21 of the last cycle of the first-line chemotherapy. Secondary outcomes were incidences of VTE events in various subgroups and overall survival.

Time to VTE was calculated from the start date of chemotherapy to date of VTE diagnosis. Log-rank test was used to compare the differences between time to VTE between patients with and without prophylaxis.

Median follow-up was calculated as median time of observation of study patients. Overall survival was calculated from the start date of chemotherapy to date of the last follow-up or death of the patient. Kaplan-Meier method was used to estimate overall survival. The log-rank test was used to compare 
differences in survival between patients with and without prophylaxis. All calculations were done in NCSS 2019 statistical software.[15]

\section{Results}

\section{Patients' characteristics}

Our cohort included 353 chemotherapy naive patients with GCTs treated with first line chemotherapy (Flow diagram). Patients' characteristics are summarized in Table 1. Median age of patients at time of enrollment was 32 years (ranging from 17 to 63 years). The majority of patients (75.9\%) had nonseminomatous germ cell tumor. All patients received platinum-based chemotherapy. 
Table 1

Patients' characteristics

\begin{tabular}{|c|c|c|}
\hline & $\mathbf{N}$ & $\%$ \\
\hline All & 353 & 100 \\
\hline \multicolumn{3}{|l|}{ Histology } \\
\hline seminoma & 79 & 22.4 \\
\hline NSGCT & 268 & 75.9 \\
\hline unknown & 6 & 1.7 \\
\hline \multicolumn{3}{|l|}{ Primary tumor } \\
\hline Gonadal & 318 & 90.1 \\
\hline Extragonadal & 35 & 9.9 \\
\hline Retroperitoneum & 22 & 6.2 \\
\hline Mediastinum & 10 & 2.8 \\
\hline Brain & 2 & 0.6 \\
\hline Unknown & 1 & 0.3 \\
\hline \multicolumn{3}{|l|}{ Stage } \\
\hline I.A/B & 38 & 10.8 \\
\hline I.S & 22 & 6.2 \\
\hline II.A & 30 & 8.5 \\
\hline II.B & 47 & 13.3 \\
\hline II.C & 44 & 12.5 \\
\hline III.A & 43 & 12.2 \\
\hline III.B & 42 & 11.9 \\
\hline III.C & 87 & 24.6 \\
\hline \multicolumn{3}{|c|}{ IGCCCG Risk Group } \\
\hline Stage IA/B & 38 & 10.8 \\
\hline Good & 192 & 54.4 \\
\hline Intermediate & 46 & 13.0 \\
\hline
\end{tabular}




\begin{tabular}{|lll|}
\hline & $\mathbf{N}$ & $\%$ \\
\hline Poor & 77 & 21.8 \\
\hline Treatment regimen & & \\
\hline BEP & 250 & 70.8 \\
\hline Other & 103 & 29.2 \\
\hline Follow-up status & & \\
\hline Alive & 300 & 84.99 \\
\hline Exitus & 51 & 14.45 \\
\hline Unknown & 2 & 0.57 \\
\hline $\begin{array}{l}\text { NSGCT - nonseminomatous germ cell tumor, IGCCCG - International Germ Cell Cancer Collaborative } \\
\text { Group, BEP - bleomycin, etoposide, cisplatin }\end{array}$ & \\
\hline
\end{tabular}

\section{VTE prophylaxis}

LMWH prophylaxis was administered to 104 patients (29.5\%) for the duration of hospitalization for chemotherapy, 249 patients (70.5\%) did not receive LMWH prophylaxis. Before January 2010, 7 out of $174(4.0 \%)$ patients received LMWH prophylaxis and 97 out of $179(54.2 \%)$ patients treated after January 2010 received prophylaxis (Flow diagram). The majority of patients (74.3\%) receiving LMWH prophylaxis after January 2010 were stage II.B or higher.

\section{VTE events}

In our study population, most VTE events occurred even before starting chemotherapy. We identified 41 out of $394(10.4 \%)$ patients, who developed VTE before starting treatment. These patients were excluded from the study (Flow diagram).

During the study period, we observed 14 (4.0\%) VTE events. Deep vein thrombosis was observed in 13 patients $(3.7 \%)$, and one patient $(0.3 \%)$ had pulmonary embolism. No visceral thromboses were observed. One event $(7.1 \%)$ was fatal. In patients without prophylaxis, we documented eight events (3.2\%), while six events (5.8\%) were documented in patients receiving LMWH prophylaxis. The difference was not statistically significant. $(P=0.37)$ The data are summarized in Table 2. 
Table 2

VTE events

\begin{tabular}{|c|c|c|c|c|c|}
\hline & \multicolumn{2}{|c|}{ No prophylaxis } & \multicolumn{2}{|c|}{ VTE prophylaxis } & \multirow[t]{2}{*}{ p value } \\
\hline & $\mathrm{N}$ & $\%$ & $\mathrm{~N}$ & $\%$ & \\
\hline All VTE events & $8 / 249$ & 3.2 & $6 / 104$ & 5.8 & 0.3681 \\
\hline Incidental events & $2 / 8$ & 25.0 & $4 / 6$ & 66.7 & 0.2774 \\
\hline Symptomatic events & $6 / 8$ & 75.0 & $2 / 6$ & 33.3 & \\
\hline \multicolumn{6}{|l|}{ Histology } \\
\hline Seminoma & $1 / 45$ & 2.2 & $1 / 34$ & 2.9 & 1.0000 \\
\hline NSGCT & $7 / 197$ & 3.4 & $5 / 64$ & 7.8 & 0.1653 \\
\hline \multicolumn{6}{|l|}{ Primary tumor location } \\
\hline Gonadal & $8 / 228$ & 3.5 & $4 / 90$ & 4.4 & 0.7461 \\
\hline Extragonadal & $0 / 21$ & 0.0 & $2 / 14$ & 14.3 & 0.1529 \\
\hline \multicolumn{6}{|l|}{ IGCCG risk group } \\
\hline Stage IA/B & $0 / 34$ & 0.0 & $0 / 4$ & 0.0 & 1.0000 \\
\hline Good & $4 / 135$ & 3.0 & $1 / 57$ & 1.8 & 1.0000 \\
\hline Intermediate & $1 / 31$ & 3.2 & $2 / 15$ & 13.3 & 0.2444 \\
\hline Poor & $3 / 49$ & 6.1 & $3 / 28$ & 10.7 & 0.6622 \\
\hline \multicolumn{6}{|l|}{ Chemotherapy regimen } \\
\hline BEP & $6 / 183$ & 3.3 & $2 / 67$ & 3.0 & 1.0000 \\
\hline Other & $2 / 66$ & 3.0 & $4 / 37$ & 10.8 & 0.1844 \\
\hline
\end{tabular}

Out of the fourteen VTE events, 8 events were symptomatic, and 6 events were incidental. There were two symptomatic VTE events in patients receiving LMWH prophylaxis and six symptomatic events occurred in patients without prophylaxis ( $75 \%$ vs $33.3 \%, P=0.28)$. In patients who experienced VTE, median time to VTE was 28.5 days (15-83 days) in patients without prophylaxis and 53.5 days (1-92 days) in patients with prophylaxis (hazard ratio $(\mathrm{HR})=0.53,95 \% \mathrm{Cl} 0.17-1.7, \mathrm{P}=0.24$ ).

Incidence of VTE in patients without prophylaxis before 2010 was similar to incidence of VTE in subgroup of patients with prophylaxis after 2010 , totally as well as in subgroup analysis based on IGCCCG risk group (Supplementary Table S1). 
There were 12 VTE events in patients with non-seminomatous germ cell tumors (NSGCTs) and 2 events occurred in patients with seminoma. There were no statistically significant differences in VTE incidence between patients with and without prophylaxis based on tumor histology.

Twelve VTE events (3.8\%) occurred in patients with gonadal tumors. Four events (4.4\%) occurred in patients with prophylaxis and eight events (3.5\%) occurred in patients without prophylaxis. The difference was not statistically significant $(P=0.75)$. Two VTE events occurred in patients with extragonadal tumors. Both patients received LMWH prophylaxis. The difference was not statistically significant. $(0.0 \%$ vs. $14.3 \%, P=0.15)$.

Out of the fourteen VTE events, five events occurred in patients with good risk according to IGCCCG classification, three events occurred in patients with intermediate risk and 6 events occurred in patients with poor risk. Patients with intermediate or poor risk were more likely to suffer VTE event when compared to patients with good risk according to IGCCCG classification ( $7.3 \%$ vs $2.2 \%, P=0.02)$. However, VTE incidence did not differ significantly in patients with and without prophylaxis for none of the risk groups.

Out of the fourteen patients suffering VTE events, 8 patients received bleomycin, etoposide and cisplatin (BEP), 3 patients had dose dense regimen[16], two patients received paclitaxel, bleomycin, etoposide and cisplatin and one patient was treated with etoposide and cisplatin.

In patients receiving BEP regimen, there were 2 VTE events (3.0\%) in patients receiving LMWH prophylaxis and 6 events (3.3\%) in patients without $\mathrm{LMWH}$ prophylaxis. In patients receiving chemotherapy regimen other than BEP, there were 4 events (10.8\%) in patients with LMWH prophylaxis and 2 events $(3.0 \%)$ in patients without prophylaxis. The difference was not statistically significant. $(p=0.1844)$

\section{Association between overall survival and prophylactic anticoagulation}

Median follow-up of all patients was 71 months (0-224 months). Median follow-up of alive patients was 122 months (1-224 months). There were 51 deaths (14.45\%) in our study population. 2-and 5-year overall survival of the study group was $87.99 \%$ (95\% Cl 84.49\% - 91.49\%) and $84.27 \%$ (95\% Cl $80.22 \%-$ $88.31 \%$ ), respectively. There was no difference in overall survival in patients with or without prophylaxis $(\mathrm{HR}=0.61,95 \% \mathrm{Cl} 0.32-1.13 ; \mathrm{P}=0.0784)$ (Fig. 1). The results are summarized in Table 3. Patients with extragonadal GCT and patients with NSGCT histology receiving VTE prophylaxis had significantly shorter survival compared to patients without prophylaxis $(H R=0.29,95 \% \mathrm{Cl} 0.08-1.12 ; \mathrm{P}=0.0373, \mathrm{HR}=0.50$, $95 \% \mathrm{Cl} 0.25-0.99 ; \mathrm{P}=0.0179$ respectively) (Fig. $2 \mathrm{~A}$ and $2 \mathrm{~B}$ ). We have also observed a trend to shorter overall survival in patients receiving prophylaxis with chemotherapy regimen other than $B E P(H R=0.50$, $95 \% \mathrm{Cl} 0.22-1.12 ; \mathrm{P}=0.0614)$. 
Table 3

Overall survival

\begin{tabular}{|c|c|c|c|c|c|c|}
\hline & $\begin{array}{l}\text { VTE } \\
\text { prophylaxis }\end{array}$ & $\mathbf{N}$ & HR & $\begin{array}{l}\text { lower 95\% } \\
\mathrm{Cl}\end{array}$ & $\begin{array}{l}\text { upper } 95 \% \\
\mathrm{Cl}\end{array}$ & $\begin{array}{l}p \\
\text { value }\end{array}$ \\
\hline All patients & $0 / 1$ & $249 / 104$ & 0.61 & 0.32 & 1.13 & 0.0784 \\
\hline \multicolumn{7}{|c|}{ IGCCCG risk group } \\
\hline Stage IA/B & $0 / 1$ & $34 / 4$ & 0.00 & 0.00 & 0.00 & 0.6532 \\
\hline Good & $0 / 1$ & $135 / 57$ & 1.09 & 0.12 & 9.99 & 0.9425 \\
\hline Intermediate & $0 / 1$ & $31 / 15$ & 0.72 & 0.06 & 9.36 & 0.7836 \\
\hline Poor & $0 / 1$ & $49 / 28$ & 0.69 & 0.36 & 1.33 & 0.2368 \\
\hline \multicolumn{7}{|l|}{$\begin{array}{l}\text { Chemotherapy } \\
\text { regimen }\end{array}$} \\
\hline BEP & $0 / 1$ & $183 / 67$ & 0.94 & 0.37 & 2.42 & 0.8975 \\
\hline Other & $0 / 1$ & $66 / 37$ & 0.5 & 0.22 & 1.12 & 0.0614 \\
\hline \multicolumn{7}{|c|}{ Tumor histology } \\
\hline Seminoma & $0 / 1$ & $45 / 34$ & 0.58 & 0.03 & 10.34 & 0.6988 \\
\hline NSGCT & $0 / 1$ & $204 / 64$ & 0.5 & 0.25 & 0.99 & 0.0179 \\
\hline \multicolumn{7}{|l|}{$\begin{array}{l}\text { Primary tumor } \\
\text { location }\end{array}$} \\
\hline Gonadal & $0 / 1$ & $228 / 90$ & 0.76 & 0.38 & 1.53 & 0.4178 \\
\hline Extragonadal & $0 / 1$ & $21 / 14$ & 0.29 & 0.08 & 1.12 & 0.0373 \\
\hline
\end{tabular}

We analyzed the incidence of treatment related deaths (TRD) in patients with primary extragonadal tumors and NSGCT histology based on LMWH prophylaxis. Treatment related death was defined as death during first-line chemotherapy. Patients with extragonadal tumors receiving LMWH prophylaxis had a higher incidence of TRD compared to patients without prophylaxis ( $21.4 \% \mathrm{vs} .0 .0 \%, \mathrm{P}=0.0556)$. Patients with NSGCT histology on LMWH prophylaxis also had a higher incidence of TRD compared to patients without prophylaxis. $(10.9 \%$ vs. $3.9 \%, P=0.0552)$. On subgroup analysis of patients with NSGCT histology we found that this trend was driven by TRD of patients with primary extragonadal tumors.

\section{Incidence of major bleeding during the VTE prophylaxis}

In our cohort, there were 13 patients, who suffered major bleeding (grade $3-5$ ). There were 7 patients (2.8\%) received no prophylaxis and 6 patients $(5.8 \%)$ received LMWH prophylaxis. The difference was not statistically significant $(P=0.22)$ 


\section{Discussion}

In the present study, we examined the relationship between prophylactic anticoagulation during chemotherapy and incidence of VTE events as well as the association between prophylactic anticoagulation and overall survival of GCT patients treated with first line chemotherapy. In order to assess the effect of prophylactic anticoagulation on the incidence of VTE events, we included only events occurring during first-line chemotherapy, when patients were also receiving LMWH prophylaxis.

We have observed that most VTE events occur even before the initiation of chemotherapy. There was a $4 \%$ incidence of VTE events occurring during chemotherapy. Observed incidence of VTE events is in line with the incidences reported in the literature. $[6,8,10,17-19]$ However, there is a wide variation in the reported incidences. While the lowest reported incidence is $2 \%$, in a different study, there was $23.7 \%$ incidence of thromboembolic events. $[8,19] \mathrm{A}$ significant part of this variation is probably caused by different inclusion criteria: including arterial events, including patients with VTE events before the start of chemotherapy, and events occurring several months after chemotherapy. Small number of patients some studies may also contribute to this variability.

We have observed no significant differences in VTE incidence between patients with and without LMWH prophylaxis. While there have been several studies assessing VTE incidence and identifying VTE risk factors in GCT patients, most of them included only a small number of the study patients with LMWH prophylaxis. Solari et al. compared the incidence of thromboembolic events in patients receiving limited and extended LMWH prophylaxis. Limited prophylaxis was administered only during hospitalization. Extended prophylaxis was administered daily from the first day of the first cycle to day 21 of the last cycle of chemotherapy. They did not observe significant differences between these two groups. However, their study did not include a control group with no prophylaxis and therefore the effect of LMWH prophylaxis cannot be assessed. Paradoxically, the incidence of thromboembolic events reported in their study (23.7\%) was much higher than in other studies.[19] However, arterial events were also included in their analysis. Gizzi et al also compared the VTE incidence in GCT patients with and without LMWH prophylaxis. In their study, prophylaxis was administered to a subgroup of patients with risk factors for VTE (elevated lactate dehydrogenase or high body surface area). They have observed no statistically significant difference in VTE incidence between the two groups. However, neither the type of LMWH used nor the dosing of prophylaxis are mentioned.[12]

Unexpectedly, there was a trend to shorter overall survival in our patients who received LMWH prophylaxis. On further analysis we found a significantly shorter overall survival in patients receiving LMWH prophylaxis with NSGCT histology or extragonadal tumor location.

Prospective study assessing the effect of prophylactic anticoagulation in patients with GCT receiving chemotherapy compared to no prophylaxis is lacking. However, the data available suggest that LMWH prophylaxis does not offer the expected benefits in terms of decreased incidence of VTE events in GCT patients. $[12,19]$ On the contrary, our data suggest that administering LMWH prophylaxis might confer a higher risk for treatment related deaths in patients with extragonadal tumors. Given the small number of 
patients with extragonadal tumors included in our study and selection bias, this result is only hypothesis generating. Further research should focus on examining the possible association between LMWH and increased incidence of TRDs. In October 2019, American Society of Clinical Oncology published an updated guideline on the use of thromboprophylaxis in cancer patients. According to this guideline, hospitalized patients with active malignancy without additional risk factors may be offered pharmacologic thromboprophylaxis. However, routine use of thromboprophylaxis in cancer patients hospitalized solely for administration of chemotherapy is no longer recommended.[20]

To the best of our knowledge, this is the largest study evaluating the effect of LMWH prophylaxis on VTE incidence in GCT patients receiving chemotherapy. Our study has several limitations. First of all, LMWH prophylaxis was not random, possibly causing selection bias. It is possible that patients at higher risk for VTE were given thromboprophylaxis more frequently what could in turn obscure the effect of thromboprophylaxis. However, incidence of VTE in patients without prophylaxis before 2010 was similar to incidence of VTE in subgroup of patients with prophylaxis after 2010, totally as well as in subgroup analysis based on IGCCCG risk group (Supplementary Table S1). This support the conclusion of no beneficial effect of prophylaxis in GCTs patients. Secondly, the study has retrospective design. Some VTE events could have been missed as a result of incomplete medical records.

\section{Conclusion}

In conclusion in this large retrospective analysis, we showed that LMWH prophylaxis was not associated with decreased VTE incidence. Moreover, there was a higher incidence of treatment related deaths in patients with extragonadal tumor location. Taking into account these data, LMWH prophylaxis during hospitalization should not be used in GCT patients receiving chemotherapy.

\section{Abbreviations}

BEP - bleomycin, etoposide, cisplatin

$\mathrm{Cl}$ - confidence interval

GCT - germ cell tumor

HR - hazard ratio

IGCCCG - International Germ Cell Cancer Collaborative Group

LMWH - low molecular weight heparin

NSGCT - non-seminomatous germ cell tumor

$\mathrm{RR}$ - relative risk 
TRD - treatment related death

VTE - venous thromboembolism

\section{Declarations}

\section{Ethics approval}

The Institutional Review Board of the National Cancer Institute, Bratislava, Slovakia approved this study and granted a waiver of consent form for the collection, analysis and publication of the retrospectively obtained and anonymised data for this non-interventional study.

\section{Consent for publication}

Not applicable.

\section{Availability of data and materials}

The dataset supporting the conclusions of this article is included within the article.

\section{Competing interests}

None declared.

\section{Funding}

This work was supported by the VEGA Grant Agency of the Slovak Republic (VEGA 1/0043/18) and the Slovak Research and Development Agency (grant APVV-15-0086) and Ministry of Health (MZ SR 2018/39-LFUK-13). The sponsors played no direct role in the study.

\section{Authors' contributions}

$\mathrm{NH}, \mathrm{MCh}, \mathrm{KR}, \mathrm{KK}, \mathrm{JO}, \mathrm{PP}, \mathrm{VDE}, \mathrm{ZSM}, \mathrm{JM}$ and MM participated in the conception and design, acquisition, analysis and interpretation of data. $\mathrm{NH}$ drafted the article and all authors revised it critically for important intellectual content. All the authors read this manuscript and give the final approval of the version to be published. 


\section{Acknowledgements}

We would like to acknowledge Mrs Daniela Slackova, from the Population Registry of Slovak Republic for help with updating patients' database and Dr Maria Reckova for discussions and critical input. We would like to acknowledge Dr.Daniela Světlovská for administration support.

\section{References}

1. Bray F, Richiardi L, Ekbom A, Pukkala E, Cuninkova M, Moller H: Trends in testicular cancer incidence and mortality in 22 European countries: continuing increases in incidence and declines in mortality. Int J Cancer 2006, 118(12):3099-3111.

2. Nigam M, Aschebrook-Kilfoy B, Shikanov S, Eggener S: Increasing incidence of testicular cancer in the United States and Europe between 1992 and 2009. World J Urol 2015, 33(5):623-631.

3. Siegel RL, Miller KD, Jemal A: Cancer statistics, 2019. CA Cancer J Clin 2019, 69(1):7-34.

4. Timp JF, Braekkan SK, Versteeg HH, Cannegieter SC: Epidemiology of cancer-associated venous thrombosis. Blood 2013, 122(10):1712-1723.

5. Hisada Y, Mackman N: Cancer-associated pathways and biomarkers of venous thrombosis. Blood 2017, 130(13):1499-1506.

6. Piketty AC, Fléchon A, Laplanche A, Nouyrigat E, Droz JP, Théodore C, Fizazi K: The risk of thromboembolic events is increased in patients with germ-cell tumours and can be predicted by serum lactate dehydrogenase and body surface area. Br J Cancer 2005, 93(8):909-914.

7. Levitan N, Dowlati A, Remick SC, Tahsildar HI, Sivinski LD, Beyth R, Rimm AA: Rates of initial and recurrent thromboembolic disease among patients with malignancy versus those without malignancy. Risk analysis using Medicare claims data. Medicine (Baltimore) 1999, 78(5):285-291.

8. Honecker F, Koychev D, Luhmann AD, Langer F, Dieckmann KP, Bokemeyer C, Oechsle K: Venous thromboembolic events in germ cell cancer patients undergoing platinum-based chemotherapy. Onkologie 2013, 36(11):663-668.

9. Bezan A, Posch F, Ploner F, Bauernhofer T, Pichler M, Szkandera J, Hutterer GC, Pummer K, Gary T, Samonigg $\mathrm{H}$ et al: Risk stratification for venous thromboembolism in patients with testicular germ cell tumors. PLoS One 2017, 12(4):e0176283.

10. Weijl NI, Rutten MF, Zwinderman AH, Keizer HJ, Nooy MA, Rosendaal FR, Cleton FJ, Osanto S: Thromboembolic events during chemotherapy for germ cell cancer: a cohort study and review of the literature. J Clin Oncol 2000, 18(10):2169-2178.

11. Paffenholz P, Grein K, Heidegger I, Nestler T, Grabbert M, Salem J, Hellmich M, Pfister D, Heidenreich A: Predictors of thrombosis in testicular cancer during platinum-based chemotherapy. World J Urol 2019, 37(9):1907-1916. 
12. Gizzi M, Oberic L, Massard C, Poterie A, Le Teuff G, Loriot Y, Albiges L, Baciarello G, Michels J, Bossi A et al: Predicting and preventing thromboembolic events in patients receiving cisplatin-based chemotherapy for germ cell tumours. Eur J Cancer 2016, 69:151-157.

13. AkI EA, Kahale LA, Hakoum MB, Matar CF, Sperati F, Barba M, Yosuico VED, Terrenato I, Synnot A, Schunemann H: Parenteral anticoagulation in ambulatory patients with cancer. Cochrane Database Syst Rev 2017, 9:Cd006652.

14. Lyman GH, Khorana AA, Falanga A, Clarke-Pearson D, Flowers C, Jahanzeb M, Kakkar A, Kuderer NM, Levine MN, Liebman $\mathrm{H}$ et al: American Society of Clinical Oncology guideline: recommendations for venous thromboembolism prophylaxis and treatment in patients with cancer. J Clin Oncol2007, 25(34):5490-5505.

15. NCSS 2019 Statistical Software. In. Kaysville, Utah, USA: NCSS, LLC; 2019.

16. Fizazi K, Pagliaro L, Laplanche A, Flechon A, Mardiak J, Geoffrois L, Kerbrat P, Chevreau C, Delva R, Rolland $\mathrm{F}$ et al: Personalised chemotherapy based on tumour marker decline in poor prognosis germcell tumours (GETUG 13): a phase 3, multicentre, randomised trial. Lancet Oncol 2014, 15(13):14421450.

17. Moore RA, Adel N, Riedel E, Bhutani M, Feldman DR, Tabbara NE, Soff G, Parameswaran R, Hassoun $\mathrm{H}$ : High incidence of thromboembolic events in patients treated with cisplatin-based chemotherapy: a large retrospective analysis. J Clin Oncol 2011, 29(25):3466-3473.

18. Cantwell BM, Mannix KA, Roberts JT, Ghani SE, Harris AL: Thromboembolic events during combination chemotherapy for germ cell-malignancy. Lancet 1988, 2(8619):1086-1087.

19. Solari L, Kronig M, Ihorst G, Drognitz K, Heinz J, Jilg CA, Schultze-Seemann W, Engelhardt M, Waller CF: High Rates of Thromboembolic Events in Patients with Germ Cell Cancer Undergoing CisplatinBased Polychemotherapy. Urol Int 2016, 96(4):399-405.

20. Key NS, Khorana AA, Kuderer NM, Bohlke K, Lee AYY, Arcelus JI, Wong SL, Balaban EP, Flowers CR, Francis CW et al: Venous Thromboembolism Prophylaxis and Treatment in Patients With Cancer: ASCO Clinical Practice Guideline Update. J Clin Oncol 2019:Jco1901461.

\section{Figures}




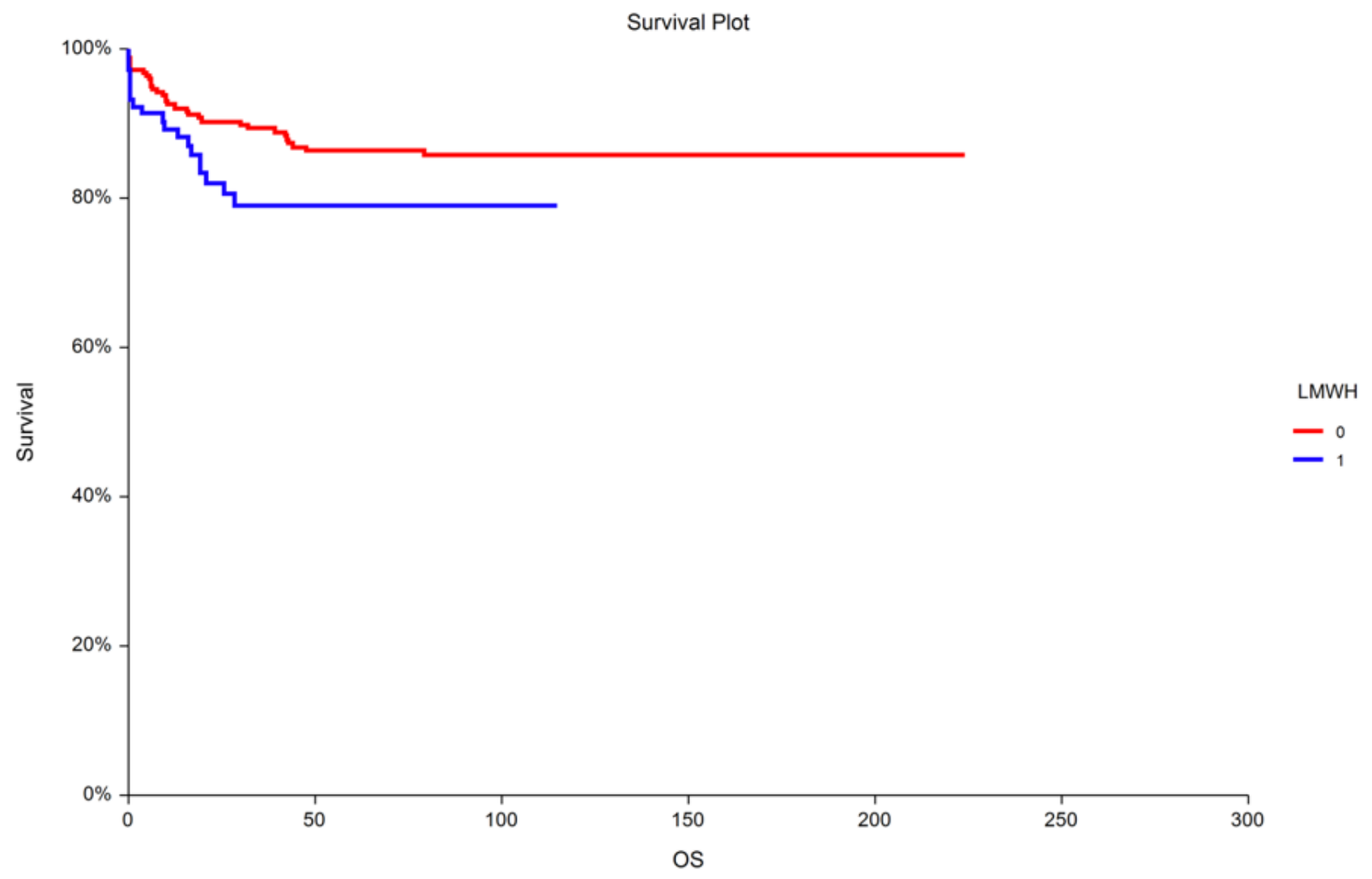

Figure 1

Kaplan-Meier estimates of probabilities of overall survival according to VTE prophylaxis in testicular germ cell tumor patients $(n=353), H R=0.61,95 \% \mathrm{Cl} 0.32-1.13 ; P=0.0784,0-$ no prophylaxis, 1 prophylaxis 


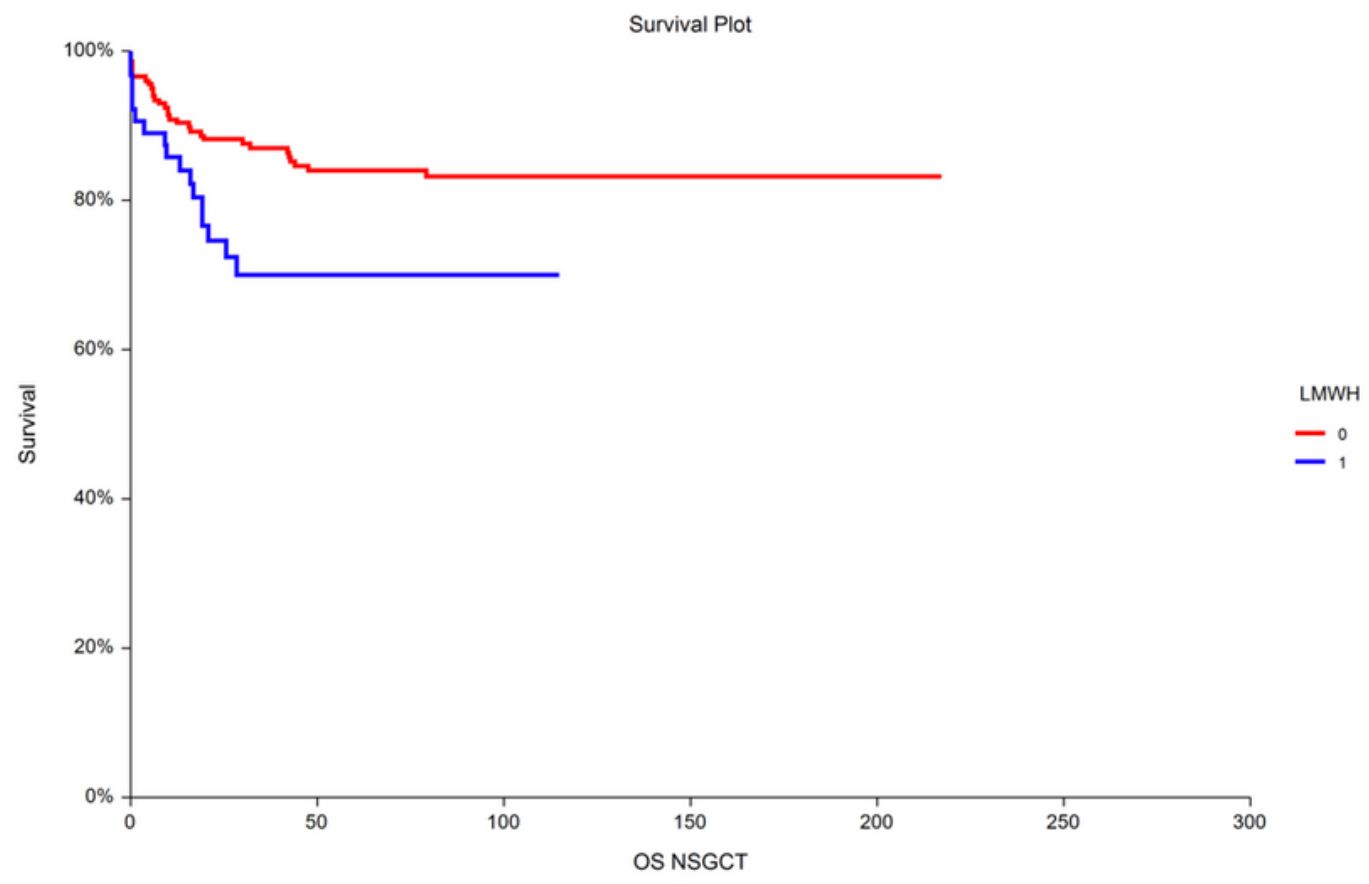

B

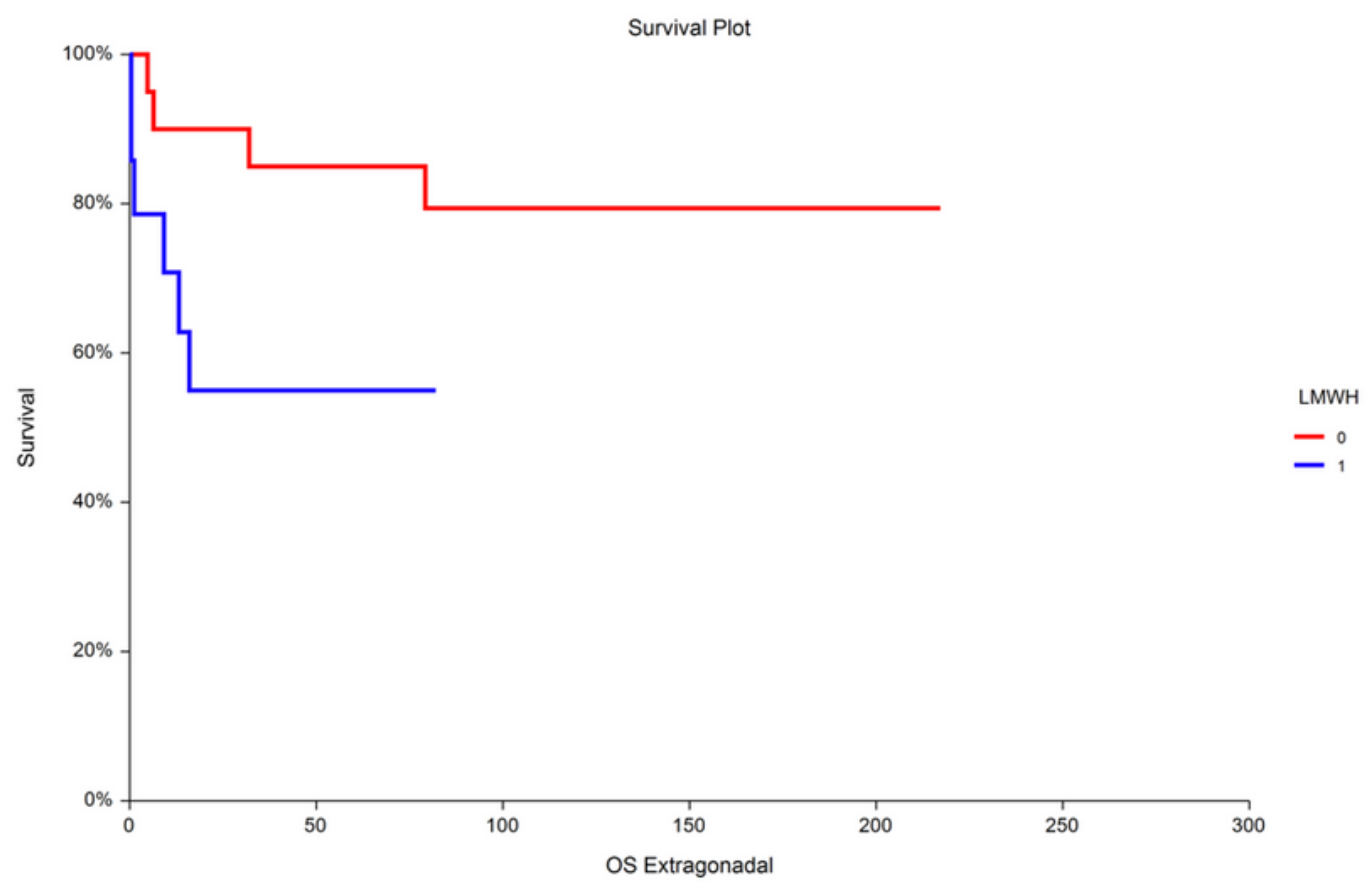

\section{Figure 2}

A Kaplan-Meier estimates of probabilities of overall survival according to VTE prophylaxis in testicular germ cell tumor patients $(n=268), H R=0.29,95 \% \mathrm{Cl} 0.08-1.12 ; P=0.0373,0-$ no prophylaxis, 1 prophylaxis. B Kaplan-Meier estimates of probabilities of overall survival according to VTE prophylaxis in testicular germ cell tumor patients $(n=35), H R=0.50,95 \% \mathrm{Cl} 0.25-0.99 ; P=0.0179,0-$ no prophylaxis, 1 - prophylaxis 


\section{Supplementary Files}

This is a list of supplementary files associated with this preprint. Click to download.

- Flowdiagram.docx

- SupplementarytableS1.docx 